\title{
Teaching Practicum during Covid-19 Pandemic: A Review of the Challenges and Opportunities of Pre-service Teachers
}

Farzaana Abdul Kadir, Azlina Abdul Aziz

To Link this Article: http://dx.doi.org/10.6007/IJARBSS/v11-i4/9646

DOI:10.6007/IJARBSS/v11-i4/9646

Received: 01 February 2021, Revised: 13 March 2021, Accepted: 15 March 2021

Published Online: 28 April 2021

In-Text Citation: (Kadir \& Aziz, 2021)

To Cite this Article: Kadir, F. A., \& Aziz, A. A. (2021). Teaching Practicum during Covid-19 Pandemic: A Review of the Challenges and Opportunities of Pre-service Teachers. International Journal of Academic Research in Business and Social Sciences, 11(4), 1175-1183.

Copyright: (c) 2021 The Author(s)

Published by Human Resource Management Academic Research Society (www.hrmars.com)

This article is published under the Creative Commons Attribution (CC BY 4.0) license. Anyone may reproduce, distribute, translate and create derivative works of this article (for both commercial and non-commercial purposes), subject to full attribution to the original publication and authors. The full terms of this license may be seen at: http://creativecommons.org/licences/by/4.0/legalcode

Vol. 11, No. 4, 2021, Pg. 1175 - 1183

Full Terms \& Conditions of access and use can be found at http://hrmars.com/index.php/pages/detail/publication-ethics 


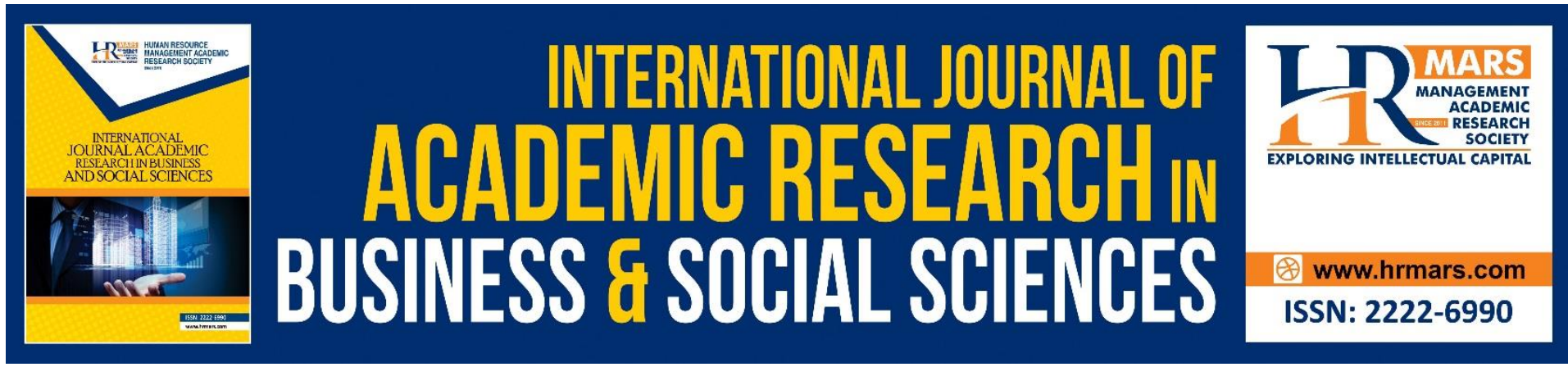

\title{
Teaching Practicum during Covid-19 Pandemic: A Review of the Challenges and Opportunities of Pre-service Teachers
}

\author{
Farzaana Abdul Kadir \\ Faculty of Education, National University of Malaysia Bangi, Malaysia \\ Email: p108980@siswa.ukm.edu.my \\ Azlina Abdul Aziz \\ Faculty of Education National University of Malaysia Bangi, Malaysia \\ Email: azlina1@ukm.edu.my
}

\begin{abstract}
Teacher education programme around the world is divided into two parts, learning the theories, and then practising them before stepping into the real world of teaching. Practising teaching or better known as teaching practicum during the final year of the teacher education programme completes the pre-service teachers' eligibility to be a teacher, from a pre-service teacher. Therefore, teaching practicum is a crucial part of the teacher education programme. As the Covid-19 pandemic strikes the world, it impacted the world in many ways including disrupting teacher education as teaching practicum cannot be carried out as usual due to educational institutions such as universities and schools' closure. New dimensions of teaching practicum emerge to cope with the pandemic, different dimensions of challenges and opportunities of teaching practicum emerge too with that. This paper reviews the challenges and opportunities of teaching practicum of pre-service teachers during the Covid-19 pandemic era. The paper then reveals some implications for the teacher education programme with regards to teaching practicum.
\end{abstract}

Keywords: Teaching Practicum, Challenges, Opportunities, Covid-19, Pre-service Teachers

\section{Introduction}

Due to the Covid-19 pandemic outbreak, many countries in the world declared closure of educational institutions. This leads to an interruption in the teaching and learning process which therefore causes a shift to the virtual process for it to keep going (Nurfaradilla et al. 2020; Özkanal, Yüksel \& Uysal, 2020). As the educational institutions including schools and universities, shift to online teaching and learning, this created a concern on pre-service teachers who need to or was going through their teaching placement which they must fulfil based on the given duration by their universities to complete their teacher education (Özkanal, Yüksel \& Uysal, 2020). Teaching practicum is considered an important stage in teacher training as both theory and practice are combined to provide opportunities for pre- 
service teachers to enhance their learning, in addition to being an essential component to prepare them to become effective teachers (Darling-Hammond, 2017).

Education institution closure due to the increasing numbers of Covid-19 cases enforced the teacher education programme providers to find various ways and come out with new dimension of teaching practicum to fit into the virtual process of teaching and learning made by tertiary education and schools to make sure the pre-service teachers will be ready for their real teaching journey (Sasaki et al., 2020; Sepúlveda-Escobar et al., 2020). Osman (2020) described online teaching practicum as a new dimension to teaching practicum which acts as a platform where pre-service teachers' offline and online teaching and learning skills in addition to their technical skills and instructional design are strengthened.

Many studies have been done on virtual teaching and learning practice yet virtual teaching practicum and the experience it offers has been overlooked (Sepúlveda-Escobar et al., 2020) but started to gain attention during the pandemic. The pandemic has caused teaching practicum to be adapted into a virtual environment and hence, new dimensions of teaching practicum occur. The new dimensions brought a new experience of teaching practicum for pre-service teachers. Therefore, this paper reviews pre-service teachers' challenges and opportunities of teaching practicum during the Covid-19 pandemic.

\section{The New Dimensions of Teaching Practicum during Covid-19 Pandemic Outbreak}

In order to continue the teaching and learning process during the pandemic, both asynchronous and synchronous teaching and learning were conducted via different platforms for visualisation such as Blackboard, Microsoft Teams, Google Hangout Meet, Panopto, OneNote, BlueSky, WhatsApp and Skype (Sepulveda- Escobar et al., 2020). Besides that, Moodle was also used to continue the teaching and learning process (Osman 2020). Some implementations were introduced to replace face-to-face teaching including teaching practicum.

An online teaching practicum course which undergoes a well-thought process from planning where the pre-service teachers are prepared and trained for the practicum, followed by the implementation where the teaching practicum and supervision took place and lastly reflection of pre-service teachers' experience of their lessons and distance education was designed by Kim (2020). This online course served as a replacement for face-to-face teaching practicum for pre-service teachers in a college in the USA. Kim (2020) claimed that pre-service teachers should be given the opportunity to teach online and reflect on their teaching to develop better. Through the course designed, pre-service teachers also observed and reflected on each other's online lessons. The process of designing the course was wellthought as the pre-service teachers were given guidance before going for online teaching practicum and given a chance to reflect on their practice after teaching practicum.

Besides that, teaching practicum via WhatsApp was introduced by Nel and Marais (2020). Usage of WhatsApp for teaching practicum could increase the accessibility of students to the content delivered because it is also one of those platforms which are low cost and requires low technology to use. However, utilising only WhatsApp, there were no live interactions among pre-service teachers and their students which is seen as a limitation (Nel \& Marais 2020). Osman (2020) argued that online teaching and learning acts as an alternative but live interaction is still required to accommodate the online environment. Although there were positives in using WhatsApp for teaching practicum, the limitations were also there. Having minimal 'live' interaction via WhatsApp video call might have enhanced the teaching and 
learning experience, taking into account the importance of 'live' interaction between student and teachers.

For Sultan Qaboos University's pre-service teachers, they continued teaching practicum online after five weeks of face-to-face practicum with the schools they were placed at via a new dimension of teaching practice where their technical and design skills were sharpened (Osman 2020). This was due to conducting lessons in many different ways such as using Schoology, Google Classroom, Seesaw and Moodle besides asynchronous lessons via videotaping and broadcasting lessons. For the implementation of Emergency Remote Learning (ERL) in relation to pre-service teachers' education programme and practicum, Sultan Qaboos University, 24/7 hotline through WhatsApp was implemented for technical support was provided in addition to webinars and training to maximize usage of online tools for teaching and learning (Osman, 2020).

Due to the lockdown (Özkanal, Yüksel \& Uysal, 2020) in their study revealed that pre-service teachers in Turkey who underwent 5 weeks of face-to-face teaching practicum was not able to continue with their placement and therefore, they were assigned to observed and reflect on the lessons on EBA TV which was an initiative of the Ministry of Education in Turkey to keep teaching and learning going. In this case, their online teaching practicum was online observations. The EFL pre-service teachers critically evaluated the EBA TV lessons and gave suggestions to improve the lessons. Özkanal, Yüksel \& Uysal (2020) mentioned that their reflection-on-action practice was an implementation to cater to teaching practicum and give them an opportunity to enhance their professional development. This claim is backed by (Salajan and Duffield 2019) who also stated that reflection-on-action results in professional development. Schon's (1987) reflection framework was reconceptualised to examine the preservice teachers' reflection-on-action experience of in-service and expert teachers teaching via broadcasting on the EBA TV (Özkanal, Yüksel \& Uysal, 2020). Yalçın Arslan (2019) claimed that reflective practice is proven to make positive progress in pre-service teachers teaching experience via their longitudinal case study on pre-service teachers' reflection-on-action.

Ersin, Atay, \& Mede (2020) designed "e-practicum" as an alternative to teaching practicum to make sure the pre-service teachers received a quality teaching practice besides preparing them for teaching online. University supervisors were assigned as the "e-mentor" where they work on supervising the pre-service teachers to become competent teachers and at the same time be able to gain positive experience teaching online. Using Zoom as the platform for virtual classrooms, the pre-service teachers conducted microteaching where some of them also acted as students. After each lesson, university supervisors or e-mentors provided their feedback which is then followed by each pre-service teacher's reflection on their experience of e-practicum and e-mentoring. Based on Ersin, Atay, \& Mede (2020), e-practicum they implemented impact pre-service teachers positively as they were able to defeat their online teaching anxieties.

\section{Pre-service Teachers' Challenges and Opportunities of Online Teaching Practicum}

As teaching practicum was adapted in various dimensions virtually, pre-service teachers experience on the shift of traditional teaching practicum to online teaching practicum consist of both the good and the bad or the challenges which they have to faced and opportunities which they got during their teaching practice in Covid-19 era. Moreover, according to (Evagorou and Nisiforou 2020) not all pre-service teachers projected a high level of readiness for online teaching. Therefore, various challenges were faced by pre-service teachers 
depending on the context, contact and the way in which online teaching practicum was conducted.

\section{Challenges}

One of the challenges of online teaching practicum was the lack of 'live' communication between pre-service teachers and students (Sepulveda-Escobar et al., 2020). Lack of interaction is a huge disadvantage of online lessons (Özkanal, Yüksel \& Uysal, 2020). Sepulveda-Escobar et al (2020) argued that lack of interaction between pre-service teachers and students during the online teaching placement might impact pre-service teachers' professional development namely social and personal development. On the students' development part, Kim (2020) found that pre-service teachers teaching kindergarten students were not able to conduct enough hand-on activities online which is considered a crucial part of learning for young children. Furthermore, due to lack of interaction, it was challenging for pre-service teachers to acknowledge and adjust the content to meet students' individual needs (Nel and Marias, 2020; Kim, 2020). Pre-service teachers should learn to multitask where they could create different activities to cater for students. Supporting this claimed, Kim (2020) stated that it is a must to multi-task for online teaching. Because for a successful teaching and learning process, students' needs must be taken into account (Osman, 2020). However, this is only possible if the pre-service teacher and student have more 'live' interaction from which the teachers could know their learners' needs better.

Pre-service teachers also struggled in technological integration and material preparation as they lack experience and expertise in utilising technology and digital materials (Ersin, Atay, \& Mede, 2020). Materials play a significant role in the success of online education (Özkanal, Yüksel \& Uysal, 2020). Due to lack of knowledge, some pre-service teachers were not able to engage their audience with the materials they prepared where the activities were not transformed in such a way that they would be suitable for online teaching and learning (Evagorou and Nisiforou, 2020). This was the main challenge of pre-service teachers who were involved in an online STEM fair as part of their teaching practicum experience (Evagorou and Nisiforou, 2020). Through observation and reflection of EFL pre-service teachers of the lessons on EBA TV, they found that using realia in online lessons could help to motivate and attract students better (Özkanal, Yüksel \& Uysal, 2020). Therefore, pre-service teachers could adopt this strategy and use realia in their online lessons to promote active participation among students. Moreover, for pre-service teachers teaching via WhatsApp, using the messenger to deliver content via video clips was challenging as they were not able to compress the video clips, in order to support, usage of PowerPoint presentation with voice over was introduced including in details guidelines were provided for pre-service teachers (Nel and Marais, 2020). Nel and Marais (2020) stated that the guidelines work wonders without having physical support for technical specialists. Thus, providing proper, concise and constructive guidelines may help pre-service teachers to integrate technology and prepare materials for successful lessons.

Besides that, the limitation of access faced by students created a barrier for pre-service teachers to conduct lessons and therefore, they were permitted to teach via asynchronous and synchronous platforms (Nurfaradilla et al., 2020). This contradicts Kim (2020) who argued that online teaching is limitless, students can be reached despite their locations. Although online teaching is limitless, access can be a limitation to reach the students. Due to this issue, some pre-service teachers were only able to carry out their lessons once a week (Nurfaradilla et al. 2020). Even though there were limitations, pre-service teachers were keen to teach 
which may be due to the empathy they felt for their students to not be left out in this testing time (Sepulveda-Escobar et al., 2020). Highlighting this statement, Nurfaradilla et al. (2020) revealed that due to the current situation, there was an increase in the empathy for school students which encouraged pre-service teachers to work towards ensuring an effective learning process.

Last but not least, pre-service teachers claimed that there was a lack of support from and communication with their cooperative teacher which is also their mentor at schools' online placement which led to a negative factor in their development (Sepulveda-Escobar et al. 2020). This is because, via mentoring, pre-service teachers are not only guided in terms of the pedagogy but also supported in terms of professional development (Sethusha 2020). Unfortunately, based on research done by Sepulveda-Escobar et al. (2020), they found that some pre-service teachers were given administrative work instead of assigned for teaching by their cooperative teachers during their online teaching practicum. Pre-service teachers had to keep on getting back to the cooperative teachers for them to give feedback on materials they prepared for lessons (Sepulveda-Escobar et al. 2020). However, the pre-service teachers justified that this was due to the cooperative teachers also being in the adapting and learning stage of the online teaching and learning practice (Sepulveda-Escobar et al., 2020).

\section{Opportunities}

Although there are many challenges, online teaching practicum gave opportunities for preservice teachers to get familiar with technology and enhance their technological skills from practice in such a way that they learned and utilised new software and tools in addition to discovering how to use online platforms to the maximum (Sepulveda-Escobar et al., 2020). Pre-service teachers termed online teaching practicum as a "once-in-a-lifetime" experience which from their view impacts them positively for their teacher education and future careers (Sepulveda-Escobar et al., 2020). Through this practice, pre-service teachers will be more prepared for the real world where changes and adaptations are crucial to keep going and keep developing.

The interaction between pre-service teachers and their university lecturer cum teacher educators was more frequent and successful during online teaching practicum ( $\mathrm{Nel}$ and Marais, 2020). Pre-service teachers received support in terms of relationship, communication and care from the school they were placed at and from their university lecturer who also gave technical and emotional support (Sepulveda-Escobar et al. 2020). For instance, pre-service teachers were able to send their lesson plans for feedback from their university lecturer and plan a further virtual meeting if there is a need without having to travel and wait to meet which ease their interaction (Kim, 2020). Nel and Marais (2020) found that online teaching practicum allows the cooperative teachers and university lecturers to give immediate feedback and constructive support to the pre-service teachers as the pre-service teachers were able to adjust and improve themselves and their lessons accordingly. Furthermore, Kidd and Murray (2020) found that university lecturers were able to connect better with preservice teachers as the interactions were direct, isolated from the school they were placed at. Robinson and Rusznyak (2020) highlighted that university lecturers took extra responsibilities by being counsellors and health managers during this pandemic in order to support preservice teachers during their teaching practicum.

Besides that, the experience of teaching practicum during the pandemic gave pre-service teachers an opportunity to put into test their teaching skills in addition to further exploring the skills to strengthen them (Sepulveda-Escobar et al., 2020). The teaching and learning 
context was new, and pre-service teachers were able to independently explore, strategies and build new ideas to deliver content to students which also made them more responsible (Sepulveda-Escobar et al., 2020). Furthermore, they were also given a chance to learn by observing each other's teaching besides sharing their teaching ideas and feedback for each other during online teaching practicum (Kim, 2020). Normally during teaching practicum, only supervisors observe pre-service teachers and debrief them individually but in a virtual teaching environment, pre-service teachers could attend each other classes, observe, and then give feedback (Kim, 2020). Thus, pre-service teachers could further improve their teaching skills not only by evolving themselves but also by learning from each other.

Finally, online teaching practicum allowed pre-service teachers to profoundly think about the socio-cultural setting which surrounds school students and their families during the pandemic and its impact on the students' learning (Sepulveda-Escobar et al., 2020). This leads the preservice teachers to become more emphatic and consider their student's background when preparing for and delivering lessons (Sepulveda-Escobar et al., 2020). Thus, pre-service teachers portrayed a stronger will to face the online teaching challenges and conduct lessons when possible or given an opportunity to make sure their students experience successful learning and not being left out (Nurfaradilla et al. 2020).

\section{Implications for Teacher Education Programme}

Kidd and Murray (2020) suggested that due to this transition to online teaching and learning, teacher education programme should be rethought and restructured based upon the best potential technological and pedagogical knowledge mainly in terms of creating new approaches for conducting teaching practicum. This was also supported by Nurfaradilla et al. (2020) as they suggested revisiting courses offered before teaching practicum. Learning-frompractice could be the new approach to traditional teaching practice as Robinson and Rusznyak (2020) argued that it offers an impactful learning experience and is utilised by many during this pandemic. Additionally, as teaching practicum was stopped in England, teacher educators decided to develop their knowledge about the practice as they were not in the practice (Kidd and Murray, 2020). Hence, having reflective practice via observing lessons could serve as a unique experience to add up to teaching practicum where reflections from observations can be applied during teaching practicum.

Apart from that, in order to further improve online teaching practicum, WhatsApp or any similar messenger platform such as Telegram could be used as the means of communication and delivering lessons as suggested by Nel and Marais (2020). They highlighted some guidelines to use this means to the maximum, which were, technical requirements where training is given unto how to use WhatsApp; partnership requirement where the ratio of students teachers to mentor teachers and university lecturers should be carefully considered, also supported by Kim (2020); and practice-based requirements where the content should be listed based on the approval of mentor teacher and university lecturer, clear rubrics designed to smoothen assessment process and also the role of mentor teachers and university lecturers should be assigned clearly. With a focused platform used for teaching practice, the strategies for teaching that will result in excellent teaching and learning should be considered and also taking into account the 'live' interactions between students and teacher.

In terms of frameworks that could enhance teacher education programme, la Velle et al. (2020) suggested Knowledge Enhancements Framework to provision new pedagogy for Initial Teacher Education (ITE) programme. The framework includes new knowledge created by research which is then taught to teacher educators and pre-service teachers, which is then 
converted into pedagogical content knowledge and lastly utilised in online classrooms. Through this framework, the teacher education programme may bring about many new changes which not only be adapted during this testing time but also when things get back to normal. On the other hand, the "TPACK model should be adopted for online learning and should be developed among pre-service teachers, emphasizing TPK and online assessment" as suggested by (Nurfaradilla et al. 2020, pg547). Besides that, they suggested that teacher educators must work on improving their expertise in technological tools and pedagogical practice. Therefore, before any changes and implementation is made in the teacher education programme, teacher educators must undergo enough training and be exposed to enough knowledge about the changes and implementation.

\section{Conclusion and Recommendations}

To conclude, the new dimension of teaching practicum brought with it a new experience for pre-service teachers. Teaching online via multiple platforms and multiple ways of conducting the teaching proves that the education process must go on in any circumstance and teachers must be ready to adjust to the situation. As teaching practicum is one of the prerequisites to graduate as a teacher and plays a major role in teachers' development, various implementations such as having an online course to attend before teaching practicum to practice online teaching, teaching practicum via WhatsApp, e-practicum, reflecting on lessons of other teachers as part of teaching practicum and joining the schools in which pre-service teachers are based at for online teaching. The divergence in the way different educational institutions responded to teaching practicum during the pandemic and adapted it to online teaching practicum opens the opportunity for more research.

Through their online teaching experience, pre-service teachers had real-time communication issues with their students, lack of skills to handle technology for teaching, students' access issues and limited support from their cooperative teachers as the challenges they faced. However, there were also advantages of the experience where the pre-service teachers got familiar with technology which supports to improve their technological skills, more successful interaction and support from university supervisors, opportunity to further explore their strength as teachers and lastly, knowing their students' socio-cultural background better. Sepulveda-Escobar et al. (2020) encouraged teacher education programme providers to actively investigate the experience of pre-service teachers during their online teaching practicum so that their development could be reinforced. Therefore, more research should be conducted to further explore this topic as this will give more insight into the enhancement of future teacher education programme.

This review attempt to benefit the teacher educators and cooperating teachers as they will be able to reflect on the experience of the pre-service teachers and may work on finding ways to accommodate the pre-service teachers' practicum for better results via various dimension of teaching practicum. Besides that, the school administrators may get insights on the issues faced for the online teaching and learning process mainly in terms of the platforms which are available to be used and to identify the challenges which may be experienced by their preservice teachers and students. Last but not least, this paper may act as a reference for teacher education programme providers for better insights on the adaptations of teaching practicum during the pandemic era and how the changes affected the pre-service teachers so that they can come out with the best adaptation of teaching practicum. With this, pre-service teachers will undergo an impactful and fruitful teaching practice experience. 


\section{Reference}

Darling-Hammond, L. (2017). "Teacher Education around the World: What Can We Learn from International Practice?" European Journal of Teacher Education 40 (3): 291-309.

Ersin, P., Atay, D., \& Mede, E. (2020). "Boosting Preservice Teachers' Competence and Online Teaching Readiness through E-Practicum during the COVID-19 Outbreak." International Journal of TESOL Studies, 2(2), 112-124.

Evagorou, M., \& Nisiforou, E. (2020). "Engaging Pre-service Teachers in an Online STEM Fair during COVID-19." Journal of Technology and Teacher Education, 28(2), 179-186.

La Velle, L., Newman, S., Montgomery, C., \& Hyatt, D. (2020). "Initial teacher education in England and the Covid-19 pandemic: challenges and opportunities." Journal of Education for Teaching, 1-13.

Kidd, W., \& Murray, J. (2020). "The Covid-19 pandemic and its effects on teacher education in England: how teacher educators moved practicum learning online." European Journal of Teacher Education, 43(4), 542-558.

Kim, J. (2020). "Learning and teaching online during Covid-19: Experiences of pre-service teachers in an early childhood education practicum." International Journal of Early Childhood, 52(2), 145-158.

Nel, C., \& Marais, E. (2020). "Preservice teachers use of WhatsApp to explain subject content to school children during the COVID-19 pandemic." International Journal of WorkIntegrated Learning, 21(5), 629.

Osman, M. E. (2020). "Global impact of COVID-19 on education systems: the emergency remote teaching at Sultan Qaboos University." Journal of Education for Teaching, 1-9.

Özkanal, Ü., Yüksel, I., \& Uysal, B. Ç. B. (2020). "The Pre-Service Teachers' Reflection-on-Action during Distance Practicum: A Critical View on EBA TV English Courses." Eğitimde Nitel Araştırmalar Dergisi, 8(4), 1347-1364.

Robinson, M., \& Rusznyak, L. (2020). "Learning to teach without school-based experience: conundrums and possibilities in a South African context." Journal of Education for Teaching, 1-11.

Salajan, F. D., \& Duffield, S. K. (2019). “Enhancing pre-service teachers' professional practice through reflection on the action of others: The development of the heterospective reflection framework informed by virtual field experiences." The Teacher Educator, 54(4), 333-358.

Sasaki, R., Goff, W., Dowsett, A., Parossien, D., Matthies, J., Di lorio, C., Montey, S., Rowe, S., \& Puddy, G. (2020). "The Practicum Experience during Covid-19--Supporting Initial Teacher Education Student's Practicum Experience through a Simulated Classroom." Journal of Technology and Teacher Education, 28(2), 329-339.

Sethusa, M. J. (2020). "Exploring Teaching Practice Supervisors' experiences Of Student Support In An Open, Distance And E-Learning Institution." e-Bangi, 17(8).

Sepulveda-Escobar, P., \& Morrison, A. (2020). "Online teaching placement during the COVID19 pandemic in Chile: challenges and opportunities." European Journal of Teacher Education, 43(4), 587-607.

Arslan, Y. F. (2019). "Reflection in pre-service teacher education: exploring the nature of four EFL pre-service teachers' reflections." Reflective Practice, 20(1), 111-124. 